\title{
Health facility-based maternal death audit in Tigray, Ethiopia
}

\author{
Samuel Hailu ${ }^{1}$, Fikre Enqueselassie ${ }^{2}$ Yemane Berhane $^{3}$
}

\begin{abstract}
Background: Maternal deaths are often unrecognized and improperly documented in the health system. Objective: To identify causes of maternal death occurring in hospitals and determine avoidability of maternal death. Methods: The study assessed each death for the cause and surrounding circumstances as well as avoidable factors, by reviewing two years patient and facility records and interviewing individuals who were involved in caring for the deceased. Data were collected between December 2005 and May 2006.

Result: A total of 34 maternal deaths were identified in five public hospitals in Tigray over a period of two years, of which $12(35.2 \%)$ were reported to have been avoidable. The leading causes of death were infection, haemorrhage and hypertensive disorders. Avoidable factors were mainly related to hospital service or medical factors such as lack of blood for transfusion, delay in transfusion, and inappropriate treatment. Lack of transportation and delayed careseeking also contributed to avoidable maternal deaths. The quality of medical records was very poor.

Nearly $73.5 \%$ of maternal deaths were of rural residents and $20.5 \%$ of those who died were under the age of 18 , which shows that young girls and rural residents carry significant maternal death risk.

Conclusions: Maternal deaths are not properly documented in health facilities. Improper care led to avoidable maternal death. Improving care and information systems is crucial to making pregnancy safer and reducing maternal death. [Ethiop. J. Health Dev. 2009;23(2):115-119]
\end{abstract}

\section{Introduction}

Maternal death is death of a woman while pregnant or within 42 days of termination of pregnancy, irrespective of the duration of pregnancy, from any cause related to or aggravated by the pregnancy or its management but not from accidental causes (1). Regarding the magnitude, every minute, one maternal death occurs somewhere in the developing countries (2). Maternal mortality is the tip of the iceberg (3). Giving birth should be a time of joy. But for more than half a million women each year, pregnancy and childbirth end in death (4).

In Ethiopia, maternal mortality ratio is estimated at $673 / 100,000$ live births (5). Only $5.3 \%$ of mothers had been attended at a health facility during delivery, pointing to possibility of a high maternal death ratio and disability (5). Previous studies on maternal mortality and national maternal mortality ratios (MMRs) do not tell us the real reasons why mothers die. Facility-based reviews are one way of looking beyond the numbers to understand why women die during maternity (6).

Among many risk factors, early marriage puts women at a greater risk. Statistics shows that girls who marry before the age of 18 are disproportionately affected by complicated pregnancies that may lead to maternal mortality (7).

Factors contributing to maternal death can be identified and quality of obstetric care can be improved. Therefore, this study aimed to identify causes of maternal death occurring in hospitals and to determine avoidability of those deaths.

\begin{abstract}
Methods
Study area and period: This study was conducted in five public hospitals of Tigray regional state between December 2005 and May 2006.
\end{abstract}

Study design: A cross-sectional study was conducted to retrospectively collect information on maternal deaths that occurred in five hospitals in Tigray during 20042005 .

Hospital Selection Criteria: The hospitals were selected purposively and the criteria included being referral hospital with active maternity departments that can reasonably manage maternal complications in the regional capital and outside the capital that have provided comprehensive emergency obstetric care in the past two years prior to the study.

Study population: The study population were maternal deaths happening in the selected hospitals during the years 2004 and 2005. All maternal deaths identified happening in the target year for the study were included without applying any exclusion criteria.

Data collection and sources: Maternal death was defined as any death while pregnancy or within 42 days following the end of pregnancy. However, it was difficult to strictly apply the definition of maternal deaths due to unavailability of complete medical records and death certification. Hospital registers were used to identify the maternal deaths using the following procedure by trained nurses and health officers.

${ }^{1}$ AMREF in Ethiopia, E-mail: samueltsion@yahoo.com; ${ }^{2}$ School of Public Health, Addis Ababa University, fikreens@yahoo.com; ${ }^{3}$ Addis Continental Institute of Public Health, yemaneberhane@ethionet.et 
All women who died at the age of 15-49 years were identified from the hospital's in-patient registers; deaths were then classified as maternal or not by reviewing the records and, when possible, interviews to health workers who provided care to the deceased were held. Maternal deaths were identified only using the registers; no attempt was made to go through all hospitals' patient records to identify maternal deaths. The inclusion criteria was all women who died during maternity at age 15-49 two years prior to the data collection period.

The patient medical records were then reviewed using a uniform medical information extraction form. Key data items for a complete maternal death audit are name of patient; name of next-of-kin; age; address; relevant past medical history; past obstetric history; gravidity; parity; antenatal care attended; gestation at time of death; died delivered or undelivered; place of delivery; main attendant at delivery; referral (if yes, type and name of facility referring); date of death; time of death; autopsy finding; and final diagnosis.

Health workers were interviewed. too maximize the chance of collecting all relevant information and the possibility of identifying all maternal deaths In the same manner, care providers who could be identified and traced were interviewed using a structured checklist to obtain additional information. The interviews provided useful information that helped to classify maternal deaths into avoidable or otherwise.

The plan was to interview as many health care providers as possible and we managed to interview 59, including obstetricians, medical doctors, nurses, midwives, health assistants, surgeons and internists. The attempt to fill the gap by interviewing the care provider was not successful in some cases because of the high staff turnover and the time lapse between the death and the data collection; many had already left the institutions.

It was also very difficult to assess avoidability of deaths in institutions where there is no established maternal death audit system. Also, there is no standard of classifying avoidable factors (6). The approaches used in this study to assess avoidability were interviewing the care providers involved in the care of the deceased by asking the following question: "'Do you think anything could have been done to avoid her death." if the response was yes, the type of avoidable factors were classified into three based on factors identified in available literature: such as is patient factors, transport and access factors, and is medical service factors (8).

The approach used to assess avoidability based on information from care provider has recall bias as a limitation because time has lapsed between the event and the actual data collection.
The following definitions were used in this study.

Avoidable deaths are those maternal deaths in which at least one facility staff interviewed admitted its avoidability. Avoidable factors are those factors that contribute to her death as decided by facility staff interviewed. Patient factors are factors related to delay in seeking care, home delivery while having previous bad obstetric history, and lack of antenatal care follow up. Medical avoidable factors include misguided action by staff, staff incompetence, service inadequacy and institutional delay in treating patients. Transport / access factors includes if a mother resides in a place where there is no comprehensive emergency obstetric care.

The study was reviewed by the ethics committee of the Addis Ababa University Medical Faculty and permission to conduct the study obtained from the Regional Health Bureau and respective hospitals. No register or medical record was taken out of the hospital and confidentiality of the information was assured by removing all identifying information.

\section{Results}

A total of 34 maternal deaths were identified through the register review. As shown in Table 1, about 20.5\% (7 out of 34) of the deaths were among mothers aged less than 18 years, and $73.5 \%$ (25 out of 34 ) were rural residents. Deaths were identified from all participating hospitals; 4 from St. Marry Hospital, 6 from Adigrat Hospital, 5 from Midregenet Hospital, 9 from Mekelle Hospital, and 10 from Lemlem Karl Hospital.

The mean (S.D.) walking distance between the residence of the deceased and the hospital was about eight hours. Twelve $(36 \%)$ of the deceased mothers were primigravida (Table 1).

Table 1: Socio - demographic characteristics of maternal deaths audited in hospitals, Tigray May 2006.

\begin{tabular}{lll}
\hline Characteristics & Frequency & Percentages \\
\hline Hospital & & \\
$\quad$ Mekelle & 9 & 26 \\
Adigrat & 6 & 18 \\
Axum & 4 & 12 \\
$\quad$ Shire & 5 & 15 \\
$\quad$ Lemlemkarl & 10 & 29 \\
Age in years & & \\
$\quad<18$ & 7 & 20.5 \\
19-34 & 25 & 73.5 \\
35 and above & 2 & 5.8 \\
$\quad$ Mean (S.D.) & $25.6(6.6)$ & \\
$\quad$ Range & $17-45$ & \\
Residence & & \\
$\quad$ Urban & 9 & 26.5 \\
$\quad$ Rural & 25 & 73.5 \\
Religion & & \\
$\quad$ Orthodox & 27 & 2.9 \\
$\quad$ Muslim & 1 & 17.6 \\
$\quad$ No response & 6 & \\
\hline
\end{tabular}


As shown in Table 2, $26(76.4 \%)$ of the deaths were among referral case. Of the 34 mothers 24 (70.5\%) had term pregnancy at the time of death; and about the same number of women had previous bad obstetric history but the precise nature of the history was not recorded. About half of the women were attended by skilled delivery attendants; and $28(82.3 \%)$ died after delivery. Of the 34 deaths $12(35.2 \%)$ were clearly identified as avoidable had the women obtained proper care at the right time (Table 2).

Table 2: Reproductive and obstetric history of the deceased woman, Tigray, May 2006.

\begin{tabular}{|c|c|c|}
\hline Characteristics & Frequency & Percentages \\
\hline \multicolumn{3}{|l|}{ Referral status } \\
\hline Referred & 26 & 76.4 \\
\hline Not referral & 3 & 8.8 \\
\hline Missing & 5 & 14.7 \\
\hline \multicolumn{3}{|l|}{ Died delivered } \\
\hline Yes & 28 & 82.3 \\
\hline No & 4 & 11.7 \\
\hline Missing & 2 & 5.8 \\
\hline \multicolumn{3}{|l|}{$\begin{array}{l}\text { Gestational age at time of } \\
\text { death }\end{array}$} \\
\hline Less than 37 weeks & 4 & 11.7 \\
\hline $37-42$ weeks & 24 & 70.5 \\
\hline unknown & 6 & 17.6 \\
\hline \multicolumn{3}{|l|}{ Obstetric history } \\
\hline Good & 7 & 20.5 \\
\hline Bad & 24 & 70.5 \\
\hline Missing & 3 & 8.8 \\
\hline \multicolumn{3}{|l|}{ Main attendant at delivery } \\
\hline Skilled & 16 & 48 \\
\hline Unskilled & 6 & 17.6 \\
\hline Both skilled \& unskilled & 1 & 2.9 \\
\hline Missing & 7 & 20.5 \\
\hline $\mathrm{Na}$ & 4 & 11.7 \\
\hline \multicolumn{3}{|l|}{ Avoidability of deaths } \\
\hline unavoidable & 15 & 44.1 \\
\hline avoidable & 12 & 35.2 \\
\hline Missing & 7 & 20.5 \\
\hline
\end{tabular}

Only 4 of the deceased women had recorded antenatal visits. Delivery happened in the hospital for 11 of the 34 mothers. Only one of the deceased women had a live birth. As shown in Table 3 missing and unavailable information is significant.

As shown in Table 4, the major causes of maternal deaths were haemorrhage, infection and pregnancy-induced hypertension. According to the review, delay in seeking care on the side of the women was the major contributing factor. However medical factors and lack of transportation also made significant contributions. In about a quarter $(26.5 \%)$ of the women, all three factors contributed to the death. Only about a third $(32.4 \%)$ of the women received definitive treatment at the time of death (Table 4).
Table 3: Health service utilization of the deceased woman, Tigray, Ethiopia, May 2006

\begin{tabular}{lll} 
Characteristics & Frequency & Percentages \\
\hline $\begin{array}{l}\text { Antenatal care at } \\
\text { least once }\end{array}$ & & \\
$\quad$ Yes & 4 & 11.7 \\
No & 11 & 32.3 \\
$\quad$ Missing & 19 & 55.8 \\
Place of delivery & & \\
$\quad$ Home & 16 & 47 \\
Hospital & 11 & 32.3 \\
Missing & 2 & 5.8 \\
$\quad$ Na & 5 & 14.7 \\
Outcome of new & & \\
born & & \\
Alive & 1 & 2.9 \\
Dead & 12 & 35.2 \\
Missing & 16 & 47 \\
Na & 5 & 14.7 \\
\hline
\end{tabular}

Table 4: Diagnosis at admission, cause and contributing factors to death, in deceased women, Tigray, Ethiopia, May 2006

\begin{tabular}{|c|c|c|}
\hline Characteristics & Frequency & Percentages \\
\hline \multicolumn{3}{|l|}{ Diagnosis at admission } \\
\hline Unsafe abortion & 1 & 2.9 \\
\hline Haemorrhage & 9 & 26.5 \\
\hline Infection & 8 & 23.5 \\
\hline $\mathrm{PIH}$ & 8 & 23.5 \\
\hline Obstructed labour & 8 & 23.5 \\
\hline \multicolumn{3}{|l|}{ Cause of death } \\
\hline Unsafe abortion & 1 & 2.9 \\
\hline Haemorrhage & 10 & 29.4 \\
\hline Infection & 16 & 47.1 \\
\hline $\mathrm{PIH}$ & 6 & 7.6 \\
\hline Obstructed labour & 1 & 2.9 \\
\hline \multicolumn{3}{|l|}{$\begin{array}{l}\text { Contributing factor to } \\
\text { death }\end{array}$} \\
\hline Patient factors & 26 & 81.3 \\
\hline Medical factors & 18 & 87.5 \\
\hline $\begin{array}{l}\text { Transport/ access } \\
\text { factors }\end{array}$ & 15 & 46.9 \\
\hline $\begin{array}{l}\text { Three of the contributing } \\
\text { Factors }\end{array}$ & 9 & 26.4 \\
\hline \multicolumn{3}{|l|}{$\begin{array}{l}\text { Interventions before } \\
\text { death }\end{array}$} \\
\hline Definitive treatment & 11 & 32.4 \\
\hline Supportive treatment & 23 & 67.6 \\
\hline
\end{tabular}

The quality of medical record was poor. Out of the 18 key data items, on average, 5.74 items were missing. Time of admission, discharge and follow-up of inpatients were rarely recorded. Some of the entries in the patient medical records were also lacking the signature of the attending care providers. Most of the registers and records were written clearly and contents were easy to

read. However, most of the medical records were not complete. No patient chart had all 18 key data items 
required for a maternal death audit, making it impossible to gather all the information needed for a complete audit.

\section{Discussion}

The maternal deaths identified in two-year study period are many and are cause for major concern. Many of the deaths were associated with avoidable factors that have origin in the health system effectiveness and accessibility.

The maternal deaths identified in the five hospitals during the two-year study period were probably fewer than the actual number of deaths because of missing deaths, largely incomplete registration and recording of maternal deaths; which is a very common phenomenon even in advanced health care facilities in Europe, where over half of the deaths are missed. $(9,10)$. Thus, this study could be regarded as showing just the tip of the iceberg of maternal deaths occurring in hospital settings. The number of maternal deaths occurring without reaching hospitals could even be greater and very difficult to determine. Access to maternal health services remains poor in many developing countries (2).

Although the study tried to obtain complete information in as many ways as possible, this was not an easy exercise for many reasons. The lack of a standard way of maintaining medical records posed one of the major challenges. It appears that during emergency, recordkeeping is given the least attention, probably because care providers are overwhelmed by the situation and all their attention is on saving the patient rather than taking the records. However, it is absolutely important to have a detailed medial record for every patient in order to provide proper care and follow progress more effectively. The medical information system needs to be improved to enhance the standard of care in the health system.

The gap between the time of death and the interview ranges from a few days to a few months, which limited the possibility of gathering accurate information from the care providers. It is important to conduct a maternal death audit as close as possible to the death, preferably on the day of the event or within two weeks of death (11). This is one of the major limitations of this study. However, the number of current deaths was small because of limited access to facilities at the time of the study; so it would have been impossible to get adequate sample size during the study period had we chosen to take only deaths within the last two weeks.

There were three maternal deaths in which no health care providers could be interviewed; so only information available in the medical record was used. This could be related to high staff turnover observed in many health facilities in Ethiopia or reluctance of providers to talk about deceased patients for fear of accountability. Though additional information from health care providers is useful where complete medical record is not available, that should not be reason for excluding female deaths from the maternal death audit. (6).

In this study, we observed that many women below the age of 18 years die from maternal causes. This very tragic death could be related to their physical immaturity (6). The practice of early marriage in most parts of northern Ethiopia is still very common and one of the severe consequences is untimely death of the young girls. This is compounded by unavailability of proper antenatal care during pregnancy and transportation during labour for the majority of women living in rural areas.

Although some of the women were attended by skilled attendants they were not properly handled to avoid death; since for approximately $87.5 \%$ of the deaths medical service-related factors were identified. These include lack of blood for transfusion, institutional delay in treatment, inappropriate treatment and misguided action by staff (12).

This could be associated with the quality of training of the attendants, lack of experience and lack of equipment. Proper attention needs to be given to proper training and to availing services at the right time to reduce the tragic death of mothers during pregnancy and labour.

Timely referral of women with due consideration to transportation problems also needs to be given attention. As shown in this study, the majority of the women did not receive definitive care at the hospitals, indicating that referral or care seeking was delayed and many lives were lost during the resuscitation process on arrival at the hospitals.

In this maternal death audit, the vast majority, $82.3 \%$ of the deaths, happened after the mother had delivered, the high-risk post partum period. Despite the increased risk, women are least likely to receive health care services during the postpartum period, thus highlighting what Abouzahar described as a "mismatch" between periods of high-risk and patterns of provisions and utilization of maternal care (13).

The number of maternal deaths identified in this study for the year 2004/2005 is 34; the reported number in the health information system is only 14. (14). As indicated above, hospital statistics underestimate maternal deaths. In our case, lack of properly trained statistical clerks, lack of standard care, inadequate recording, and nonavailability of death certification can be regarded as causes for underreporting.

A major problem in this study was to determine avoidable deaths and to identify avoidable factors. Avoidablity of maternal deaths was determined based on care providers' response, which was compromised by long recall period. According to the care providers lack of transportation; improper medical care due to lack of 
blood for transfusion; delay in treatment initiation; inappropriate treatment; and patient factors such as delay to seek care and home delivery while having bad obstetric history; and congenital anomalies of the vagina were important. These factors are similar to those identified by studies but the magnitude is different (15, 16).

Efforts must be strengthened to improve the situation through coordinated efforts. The main causes identified by this study (haemorrhage, infection and PIH) are very common in Ethiopia (12) and it should not be difficult to make adequate preparations to avoid death from these causes.

In conclusion, although resource and facilities did not allow a thorough maternal death audit using a large sample, this study clearly shows that the majority of maternal deaths occurring in hospitals are missed because of improper documentation.

Young girls and rural residents face significant death risks. The majority of deceased women did not receive definitive care and the result is avoidable death. It is highly recommended that action be taken to improve training of medical staff; develop and maintain standards of care for emergency obstetric care; and improve health information systems to reduce maternal deaths significantly. Proper and regular death audits need to be instituted in the health system.

\section{Acknowledgements}

The authors are grateful to the staff of Mekelle, Shire, Axum, Lemlem Karl, and Adigrat hospitals who facilitated the conduct of this study.

\section{References}

1. Abouzahar C, Wardlaw T. Maternal mortality in 2000: Estimates developed by WHO, UNICEF, UNFPA. Geneva; WHO; 2004.

2. World Health Organization. Maternal mortality in 2005: Estimates developed by WHO, UNICEF, UNFPA and the World Bank. Geneva: WHO; 2007.

3. Koblinsky MA. Beyond maternal mortality magnitude, interrelationship, and consequences of women's health, pregnancy-related complications and nutritional status on pregnancy outcomes. International Journal of Gynecology and Obstetrics 1995;48(suppl.):S21-32.
4. United Nations. The Millennium Development Goals report 2005, New York, 2005.

5. Central statistical authority (Ethiopia) and ORC Macro 2006. Ethiopia Demographic and Health Survey, 2005. Addis Ababa, Ethiopia and Calverton, Maryland, USA: Central Sstatistical Aauthority (Ethiopia) and ORC Macro.

6. World Health Organization. Beyond the numbers: Reviewing maternal deaths and complications to make pregnancy safer, World Health Organization, Geneva, Switzerland 2004.

7. UNICEF, Early mmarriage child spouses; INOCENTI DIGEST No. 7- March 2001.

8. Sudaha Salhan: Process documentation of the initiative to " improve the quality of maternal health through implementation of facility-based review of Maternal Deaths". Regional Health Forum 2005;9(1).

9. Bouvier-colle MHH, Varnox N, Costes P, Hatton F: Reasons for the underreporting of maternal mortality in France as indicated by a survey of all deaths among women of child-bearing age. Intl J Epidemiol 1991;20:717-21.

10. Atrash H, Alexander S, Berg C: Maternal mortality in developed countries: Not just a concern of the past. Obstet Gynecol 1995;86:700-5.

11. Josephine Kasolo, Mr. Chris opit and Joyce Isiko. Maternal death audit in Jinja district. Audit report. February 2002.

12. Eugene J. Kongnyuy, Grace Mlava, Nynke van den Broek. Facility-based maternal death review in three districts in the central region of Malawi: An aanalysis of causes and characteristics of maternal deaths. Women's Health Issues 2009;19(1):14-20.

13. Abouzahar C. Safe Motherhood: A brief history of the global movement 1947-2002. British Medical Bulletin 2003;67:13-25.

14. Tigary Regional Health Bureau: 1997 Ethiopian fiscal year profile, health management information system, Tigray Health Bureau, 2004.

15. Lee $\mathrm{S}$; Reproductive health and family planning in the pacific: Current situation and the way forward; Country Support Team Discussion paper 1995;14 Office for the South Pacific; Suva ,1995.

16. Gunawan spuratikto, A district based Audit of the causes and circumstances of maternal deaths in South Kalimantan, Indonesia, Bulletin of the World Health Organization 2002; 80:228-34. 